\title{
Disability inclusion in precision medicine research: a first national survey
}

\author{
Maya Sabatello, LLB, PhD ${ }^{1}{ }^{1}$, Ying Chen, MD, $\mathrm{MS}^{2}$, Yuan Zhang, MS, $\mathrm{MA}^{3}$ and \\ Paul S. Appelbaum, MD ${ }^{1}$
}

Purpose: Including people with disabilities in precision medicine research (PMR) is key for increasing cohorts' diversity, improving understanding of population health, and attaining social justice for the United States' largest health disparities group. We conducted a national survey to explore the views of people with disabilities about PMR.

Methods: An online survey was developed in disability-accessible formats. Key questions included views on PMR, willingness to participate and to provide data, perceived barriers to participation and potential remedies, and interest in engagement in the study. Analyses described results for all participants and compared results for key demographic characteristics.

Results: In total, 1294 participants completed the survey. Participants expressed strong support for PMR, and willingness to participate in PMR; to provide lifestyle, biological, and medical information; and to engage with the study. However, 76\% identified a total of 3 to 8 barriers to participation, and most would not provide environmental samples or information from their social media account(s) and activity trackers. Differences were observed across racial, ethnic, and gender groups and are discussed.

Conclusions: Barriers to disability inclusion need to be removed, and further research conducted to better understand concerns about PMR and to develop studies that resonate with the interests and needs of this population.

Genetics in Medicine (2019) 21:2319-2327; https://doi.org/10.1038/s41436019-0486-1

Keywords: disability; precision medicine research; engagement; barriers

\section{INTRODUCTION}

As precision medicine research (PMR) gains traction in the United States, there is an urgent need for including people with disabilities in PMR. Disability inclusion is key for increasing the diversity of study cohorts, for better understanding factors impacting population health, and for achieving PMR's goal of developing a new health-care model that tailors diagnosis, treatment, and prevention to individual variability in genes, environment, and lifestyle. Disability inclusion in PMR is also instrumental for attaining social justice objectives. Such inclusion would advance efforts to curtail the deep health disparities in the United States, which have particularly impacted the disabled population, ${ }^{1}$ and acknowledges the worth of people with disabilities as equal members of society.

The views of people with disabilities about PMR and, significantly, the barriers to their participation in PMR are unknown. Several studies have explored US patients' and public views on genomic research (e.g., ${ }^{2-9}$ ) and found general willingness to participate and to share data, despite concerns about privacy and misuse of their data. A 2015 survey of a population-based sample of US adults found general support for a national PMR program across age, sex, and race/ ethnicity. ${ }^{10}$ However, none of these studies focused specifically on people with disabilities or collected disability information among participants to explore how such lived experiences may impact perspectives on PMR. Because people with a disability may experience unique barriers to participation, it is impossible to generalize prior findings to people with disabilities.

Barriers to recruitment of people with disabilities into PMR may include concerns that genetic research may reawaken interest in eugenics ${ }^{11,12}$ and that focusing on the genetics of individuals with disabilities reinforces a medicalized model of disability, with its historic neglect of societal and environmental factors that disable people from fully participating in society. ${ }^{13,14}$ Participation may also be diminished by the presence of physical, communication, institutional, economic,

\footnotetext{
${ }^{1}$ Center for Research on Ethical, Legal \& Social Implications of Psychiatric, Neurologic \& Behavioral Genetics, Department of Psychiatry, Columbia University, New York, NY, USA ${ }^{2}$ New York State Psychiatric Institute, New York, NY, USA; ${ }^{3}$ Department of Biostatistics, Mailman School of Public Health, Columbia University, New York, NY, USA. Correspondence: Maya Sabatello (ms4075@columbia.edu)
} 
and attitudinal obstacles that people with disabilities face in health-care ${ }^{15}$ and research settings. ${ }^{16}$ Learning about these barriers and how they may impact the interest of people with disabilities in participation in PMR could inform the design of PMR programs and help policy-makers and researchers better understand the views and systematic challenges to inclusion of people with disabilities. Here we report the first national study of these issues.

\section{Study design}

\section{MATERIALS AND METHODS}

In March 2018, we conducted a national, Internet-based survey of people with disabilities to explore their support for PMR, willingness to participate, and barriers to participation. The survey was based on previous studies on attitudes about genomic research, especially a 2015 US population-based survey on views of PMR (with the lead author's permission). ${ }^{10}$ Disability-specific questions were developed based on scholarship on disability and health disparities, including barriers to disability inclusion in research, health care, and society. ${ }^{17}$ Throughout the study, we consulted with experts with disabilities and national organizations of people with disabilities about the survey's content, format, and programming (e.g., making the survey accessible to screen-readers, i.e., software programs that "translate" text into speech for blind people).

Survey development followed the principles of universal design, with the goal of ensuring that the instrument was accessible, easy to understand, and useful to people with a wide range of abilities. ${ }^{18}$ We worked with the Board Resource Center, a professional disability consulting company, including an advisory group comprising linguistic experts and selfadvocates with intellectual disabilities, to develop a plain language format of the study material and pilot test its comprehensibility. The questions were framed in terminology commonly used in disability studies and advocacy. For example, instead of "mental illness" or "psychiatric disorder," terms that highlight a medical classification of deficiency, we used "mental health or psychosocial disability," which reflect the disabling experiences arising from societal attitudes and restrictions on participation. Response choices consisted of dichotomized (yes/no) or predefined options. Open-ended options were included in questions about barriers and facilitators for participation. This plain language instrument was used for all participants.

The final survey was translated into American Sign Language (ASL), in collaboration with the National Association of the Deaf (NAD), and into Spanish. Spanish translation of disability-specific questions was conducted in consultation with Hispanic self-advocates with disabilities. Columbia University's Spanish Translation Center translated other survey questions. Participants chose the version of the survey (English, ASL, Spanish) they preferred. The institutional review board (IRB) at the New York State Psychiatric Institute approved the study.

\section{Survey items}

The survey first provided a short description of a hypothetical national, longitudinal PMR cohort study (Appendix A). It described the impact of genetics, environments, and lifestyle on disease; the nature of PMR; types of data collected; and data security. The description stated that cohort participants could control how their information was used in research and have access to the information collected about their health. This description was followed by 53 questions that explored views about whether PMR should be undertaken, interest in PMR participation, willingness to provide various types of data, return of results to participants, oversight for the study, privacy protections, and desire for engagement in specific aspects of the research. Additionally, the survey included disability-specific questions about barriers to participation, possible facilitators, and incentives. Other questions collected demographic information.

\section{Participants}

The eligibility criteria for study participation were $>18$ years old, with one of the following conditions: (1) blindness/low vision, (2) deafness/hard of hearing, (3) physical disability, (4) autism, (5) intellectual/other developmental disability, (6) learning disability, or (7) mental health/psychosocial disability. Potential participants were asked to indicate their age, whether they had one or more of these conditions, and if so, their primary condition.

\section{Study procedures}

Participants were recruited through several national disability organizations that offer disability-relevant information and support services, engage in advocacy, and provide educational and research opportunities. The organizations circulated invitations to the study through their listservs; NAD tweeted about the study to its members. This recruitment method allowed extensive national enrollment of people with disabilities in the study, but precluded assessment of overall response rates. Participants provided online consent, including correctly answering two questions about the study's purpose. Completion time, based on length, was estimated at 17 minutes. Participants were offered a \$25 gift card on completing the survey.

\section{Statistical analysis}

Data were collected using SurveyMonkey and transferred into SPSS (IBM) 24.0 format. All statistical analyses were performed with SAS 9.4 software. Demographic characteristics were reported as counts and percentages. Differences among groups were compared using chi-square $\left(\chi^{2}\right)$ tests for categorical variables. Linear regression was conducted for total number of barriers. All $p$ values are two-sided and for overall groups unless otherwise specified. Multiple comparisons were adjusted for the pairwise analysis using Bonferroni correction and only $p$ values $<0.0017$ were considered significant. 
Covariates were collapsed and recoded when data cells were small and to reduce the number of categories for analysis. Accordingly, race was collapsed into White, Black/African American (AA), and Other, the latter encompassing Asians, American Indians/Alaska Natives, Native Hawaiians, Pacific Islanders. Additional analysis was conducted for those who identified as male and female (the gender group of "not listed" was too small for additional analysis $[n=30])$. Household income was collapsed into lower $(<\$ 20,000)$, middle $(\$ 20,000-55,999)$, and higher $(>\$ 56,000)$ income, based on the national poverty line ( $<\$ 24,000$ per family of four) and the median household income for working age (21-64) people with disabilities ( $\$ 43,300$ in 2016$)\left(\right.$ ref. $^{19}$ ). Responses to openended questions are used to illustrate relevant issues.

\section{Study population}

\section{RESULTS}

Overall, 1496 people began the survey; 202 were removed due to ineligibility or because they omitted $>10 \%$ of the survey questions. The remaining 1294 participants who completed the survey were included in the analyses (Table 1). Among these participants, $21 \%$ each identified their primary conditions as blindness/low vision, deafness/hard of hearing, and physical disability. The remaining participants identified their primary conditions as autism (8\%), intellectual/other developmental disability (10\%), learning disability (11\%), and mental health/psychosocial disability (9\%). Twenty-five percent reported having multiple conditions. Fifty-two percent were female, $45 \%$ male, and $3 \%$ identified as neither male nor female ("not listed"). Two-thirds of participants identified as White (66\%), 17\% Black/AA, and $18 \%$ Other. Thirty-seven percent of participants identified as Hispanic. Fifty percent were $18-29$ years old, $43 \% 30-59$ years old, and $7 \%$ over 60 . Most respondents had technical training, some college education, or were college graduates (64\%); $16 \%$ had a graduate degree. Most participants were employed full (39\%) or part-time (26\%). Forty-nine percent had household incomes of $\$ 20,000-55,999$ and $32 \%$ had over $\$ 56,000$.

\section{Perspectives on PMR and willingness to participate}

Ninety-five percent of participants supported conducting the PMR study described in the survey. Differences were observed by racial $(p<0.0001)$ and gender groups $(p<0.0001)$. White participants were more likely than Black/AA $(p=0.003)$ and Other participants $(p<0.0001)$ to answer positively, as were male compared with female $(p=0.0047)$.

An overwhelming majority of participants said that they would participate in the study if asked (89\%), with $62 \%$ willing to participate for $5-10$ years and $25 \%$ for 20 years or their lifetimes. Differences were observed across racial $(p<$ $0.0001)$, ethnic $(p=0.02)$, and gender groups $(p<0.0001)$. White participants were more likely to express willingness to participate compared with Black/AA $(p=0.04)$ and Other participants $(p<0.0001)$, with Hispanic participants more willing than non-Hispanics $(p=0.02)$. Ninety-three percent
Table 1 Demographic characteristics ${ }^{a}$

\begin{tabular}{|c|c|c|}
\hline Demographic variables & $N^{\mathrm{b}}$ & $\%$ \\
\hline \multicolumn{3}{|l|}{ Primary disability/condition $(n=1294)$} \\
\hline Blindness or low vision & 271 & 21 \\
\hline Deafness or hard of hearing & 267 & 21 \\
\hline Physical disability & 273 & 21 \\
\hline Autism & 104 & 8 \\
\hline Intellectual or developmental disability & 128 & 10 \\
\hline Learning disability & 136 & 11 \\
\hline Mental health or psychosocial disability & 115 & 9 \\
\hline Multiple disabilities/conditions $(n=1294)$ & 323 & 25 \\
\hline \multicolumn{3}{|l|}{ Age $(n=1294)$} \\
\hline $18-29$ years & 646 & 50 \\
\hline $30-59$ years & 551 & 43 \\
\hline 60 or older & 97 & 7 \\
\hline \multicolumn{3}{|l|}{ Gender $(n=1190)$} \\
\hline Male & 541 & 45 \\
\hline Female & 619 & 52 \\
\hline Not listed & 30 & 3 \\
\hline \multicolumn{3}{|l|}{ Race $(n=1294)$} \\
\hline White & 850 & 66 \\
\hline Black or AA & 214 & 16 \\
\hline Other & 230 & 18 \\
\hline \multicolumn{3}{|l|}{ Ethnicity/Hispanic $(n=1212)$} \\
\hline Hispanic & 448 & 37 \\
\hline Non-Hispanic & 764 & 63 \\
\hline \multicolumn{3}{|l|}{ Education level $(n=1184)$} \\
\hline High school, GED or less & 231 & 20 \\
\hline BA/some college/vocational or technical training & 762 & 64 \\
\hline Graduate & 191 & 16 \\
\hline \multicolumn{3}{|l|}{ Household income $(n=1205)$} \\
\hline Less than $\$ 20,000$ & 230 & 19 \\
\hline$\$ 20,000$ to $\$ 55,999$ & 594 & 49 \\
\hline More than $\$ 56,000$ & 381 & 32 \\
\hline \multicolumn{3}{|l|}{ Residence $(n=1224)$} \\
\hline Urban (city) & 573 & 47 \\
\hline Suburb (neighborhood outside the city) & 545 & 44 \\
\hline Rural (in the country) & 106 & 9 \\
\hline \multicolumn{3}{|l|}{ Employment status (check all that apply) $\left(n=1278^{\mathrm{C}}\right)$} \\
\hline Full-time employment & 497 & 39 \\
\hline Part-time employment & 339 & 27 \\
\hline Stay-at-home parent & 65 & 5 \\
\hline Full-time/part-time student & 192 & 15 \\
\hline Unable to work & 25 & 2 \\
\hline Other: not employed, retired, volunteer & 244 & 19 \\
\hline
\end{tabular}

averall, 1496 people began the survey: 66 were removed due to ineligibility, i.e., they did not (1) correctly answer the informed consent questions $(n=21)$; or (2) complete the disability questions or identify as having a disability $(n=45) ; 136$ were removed because they did not answer $>10 \%$ of the other survey questions. The remaining 1294 were eligible for participation, completed the survey, and were included in the analyses.

${ }^{b}$ Note: sample size varies due to missing values.

'Respondents who provided two employment statuses (e.g., full-time employed and a student) are included in both categories; 16 respondents were excluded due to conflicting answers (e.g., both employed full-time/part-time and not employed). 
Table 2 Perspectives on precision medicine research and willingness to participate

Do you think this study should be done?

Would you participate in the study, if you were asked?

\begin{tabular}{|c|c|c|c|c|c|c|c|c|c|c|c|}
\hline \multirow{5}{*}{ Gender } & & \multicolumn{2}{|l|}{$N(\%)$} & \multirow[t]{2}{*}{$\chi^{2}$} & \multirow[t]{2}{*}{ df } & \multirow[t]{2}{*}{$p$ value } & \multicolumn{2}{|l|}{$\mathrm{N}(\%)$} & \multirow[t]{2}{*}{$\chi^{2}$} & \multirow[t]{2}{*}{ df } & \multirow[t]{2}{*}{$p$ value } \\
\hline & & Yes & No & & & & Yes & No & & & \\
\hline & Female & $586(95)$ & $32(5)$ & \multirow[t]{3}{*}{55.15} & \multirow[t]{3}{*}{2} & \multirow[t]{3}{*}{$<0.001$} & $549(89)$ & $68(11)$ & \multirow[t]{3}{*}{21.26} & \multirow[t]{3}{*}{2} & \multirow[t]{3}{*}{$<0.001$} \\
\hline & Male & $530(98)$ & $11(2)$ & & & & $503(93)$ & $36(7)$ & & & \\
\hline & Total & $1116(96)$ & $43(4)$ & & & & $1052(91)$ & $104(9)$ & & & \\
\hline \multirow[t]{2}{*}{ Race } & White & $829(98)$ & $19(2)$ & \multirow[t]{2}{*}{41.5} & \multirow[t]{2}{*}{2} & \multirow[t]{2}{*}{$<0.001^{\mathrm{a}}$} & $782(93)$ & $62(7)$ & \multirow[t]{2}{*}{43.95} & \multirow[t]{2}{*}{2} & \multirow[t]{2}{*}{$<0.001^{b}$} \\
\hline & African American (AA) & $201(94)$ & $13(6)$ & & & & $189(88)$ & $25(12)$ & & & \\
\hline \multirow[t]{4}{*}{ Income } & Less than $\$ 20,000$ & $219(95)$ & $11(5)$ & \multirow[t]{4}{*}{0.06} & \multirow[t]{4}{*}{2} & \multirow[t]{4}{*}{0.969} & $212(93)$ & $17(7)$ & \multirow[t]{4}{*}{7.72} & \multirow[t]{4}{*}{2} & \multirow[t]{3}{*}{0.021} \\
\hline & $\$ 20,000$ to $\$ 55,999$ & $568(96)$ & $26(4)$ & & & & $546(92)$ & $46(8)$ & & & \\
\hline & $\$ 56,000$ and above & $362(96)$ & $17(4)$ & & & & $331(87)$ & $48(13)$ & & & \\
\hline & Total & 1149 (96) & $54(4)$ & & & & $1089(91)$ & $111(9)$ & & & \\
\hline Education & High school, GED or less & $222(96)$ & $9(4)$ & 1.87 & 2 & 0.393 & $212(92)$ & $19(8)$ & 1.38 & 2 & 0.502 \\
\hline Ethnicity & Hispanic or Latino & $429(96)$ & $19(4)$ & 0.03 & 1 & 0.860 & $416(93)$ & $32(7)$ & 5.57 & 1 & 0.018 \\
\hline & Non-Hispanic or Latino & $729(96)$ & $34(4)$ & & & & $674(89)$ & $86(11)$ & & & \\
\hline & Total & $1158(96)$ & $53(4)$ & & & & $1090(90)$ & $118(10)$ & & & \\
\hline Neighborhood & Urban (city) & $559(98)$ & $13(2)$ & 25.71 & 2 & $<0.001^{c}$ & $521(91)$ & $50(9)$ & 15.93 & 2 & $<0.001^{d}$ \\
\hline & Suburb (neighborhood outside the city) & $515(95)$ & $29(5)$ & & & & $495(91)$ & $47(9)$ & & & \\
\hline & Rural (in the country) & $92(87)$ & $14(13)$ & & & & $84(79)$ & $22(21)$ & & & \\
\hline & Total & $1166(95)$ & $56(5)$ & & & & $1100(90)$ & $119(10)$ & & & \\
\hline
\end{tabular}

$p<0.017$ is considered significant because of multiple comparison adjustment for three-level demographic variables.

a Pairwise comparison: White vs. AA $p=0.003$; White vs. Other $p<0.001$.

bairwise comparison: White vs. Other $p<0.001$; AA vs. Other $p=0.002$.

'Pairwise comparison: Urban vs. Suburb $p=0.007$; Urban vs. Rural $p<0.001$; Suburb vs. Rural $p=0.003$.

dPairwise comparison: Urban vs. Rural $p<0.001$; Suburb vs. Rural $p<0.001$.

of men expressed willingness to participate compared with $89 \%$ of women $(p=0.01)$ (Table 2$)$.

\section{Data provision}

Participants were asked about the types of data they would agree to provide, if they participated in the study. Seventythree percent expressed willingness to provide blood and the same percentage was willing to provide other samples, like urine, saliva, or hair. Most participants were willing to provide genetic (63\%), family medical history (59\%), and lifestyle information such as exercise and diet (68\%). However, only $51 \%$ were willing to provide samples of soil or water from around their home ("environmental samples"), and only onethird would provide information from their social media account(s) (34\%) or activity tracker (e.g., "heart rate or daily number of steps from Fitbit or smartphone" [34\%]). No clear differences in willingness to provide data across disability subgroups were identified. However, smaller percentages of participants with intellectual disabilities were willing to provide most types of data (e.g., blood [59\%; $p<0.0001$ ], genetics [45\%; $p<0.0001]$ ); autistic participants were less willing to provide family history $(40 \%$; $p<0.0001)$; and deaf/ hard of hearing participants were less likely to provide genetics $(57 \% ; p=0.0481)$, other samples $(66 \% ; p=0.0063)$, and family history $(50 \% ; p=0.0009)$.

Differences were observed across ethnic, racial, and gender groups. White participants were more willing than Black/AA and the Other group to provide most types of data $(p<$ $0.0001 ; p=0.002$ for White vs. Black/AA for other samples, like urine, saliva, or hair) but not information from social media accounts. The percentages of Black/AA participants who were willing to provide environmental samples and information from their activity trackers were especially low (32\% and 20\%). Non-Hispanic participants were more likely than Hispanic participants to provide all types of data $(p=$ 0.02 lifestyle data; $p=0.005$ social media; $p<0.0001$ all other data types). Men were more likely than women to express willingness to provide genetic information $(70 \%$ vs. $63 \%$; $p=0.01)$.

\section{Barriers to participation}

Participants were asked "What may stop you from participating in the study?" and to "select all that apply" from a list of 16 possible barriers (Fig. 1). The most common barriers were 


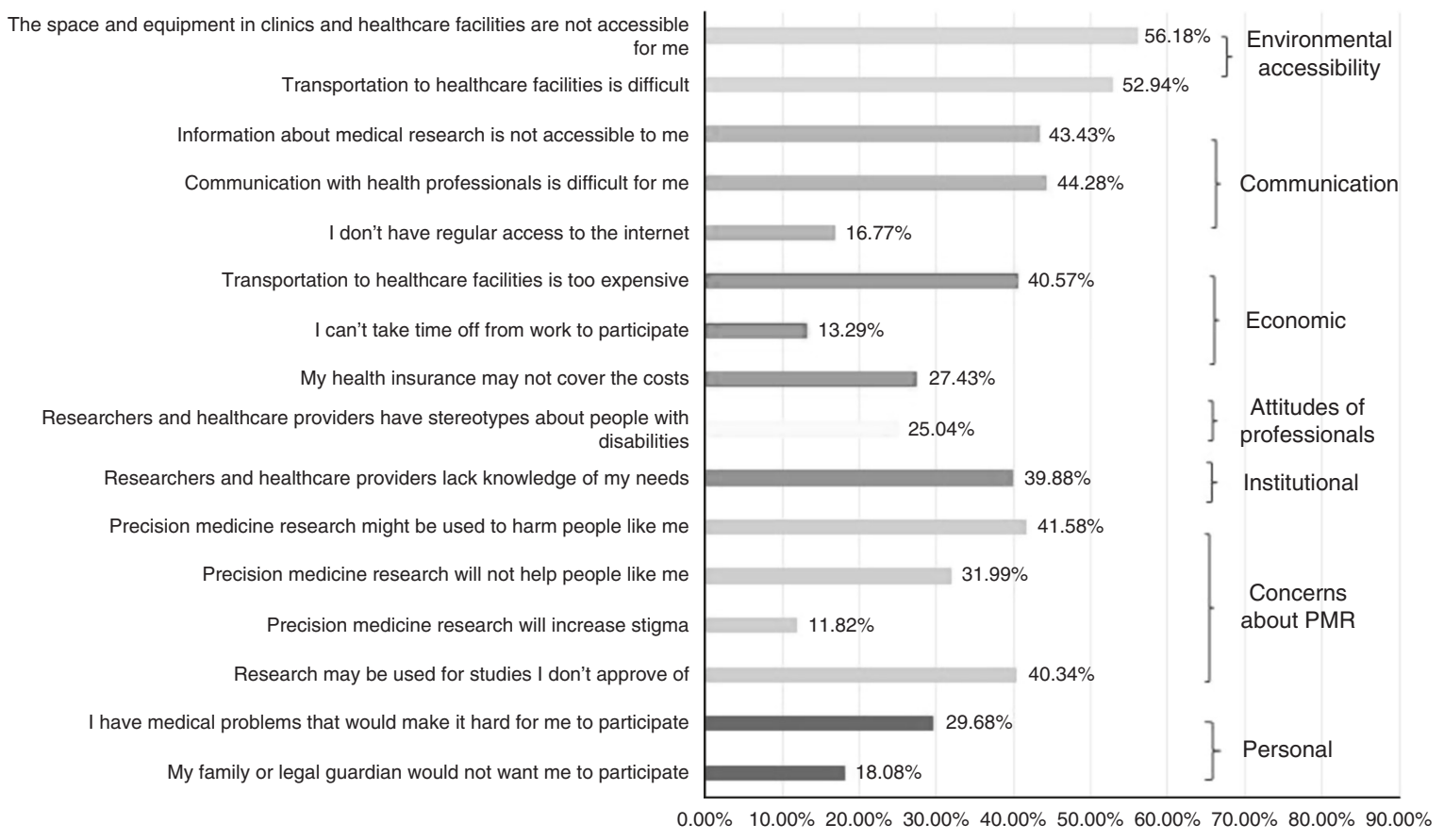

Fig. 1 Barriers to participation in precision medicine research (PMR) $(\boldsymbol{n}=1294)$.

physical obstacles: "the space and equipment in clinics and health-care facilities are not accessible for me" (56\%), and "transportation to health-care facilities is difficult" (53\%). Large minorities of participants selected: "communication with health professionals is difficult for me" (44\%), "information about medical research is not accessible to me" (43\%), "PMR might be used to harm people like me" (42\%), "transportation to health-care facilities is too expensive" (41\%), "research may be used for studies I don't approve of" $(40 \%)$, and "researchers and health-care providers lack knowledge of my needs" (40\%). In addition, about a third of participants selected "PMR will not help people like me" $(32 \%)$ and "I have medical problems that would make it hard for me to participate" (30\%). Other barriers, e.g., increased stigma and regular access to the Internet were less prevalent (ranging from $12 \%$ to $27 \%$ ). Open-ended responses noted concerns about privacy and time required for participation.

The total number of barriers identified by our participants is high: $96.6 \%$ said there was at least one barrier, including $76 \%$ who identified 3 to 8 barriers. Higher total number of barriers was associated with having intellectual disability $(p<$ $0.0001)$, being male vs. female $(p<0.0001)$, White vs. Other $(p=0.0024)$, and non-Hispanic vs. Hispanic $(p=0.0443)$, as well as with having lower income $(<\$ 20,000$ vs. higher incomes; $p<0.0001$ ).

\section{Facilitators of participation}

Participants were asked "What would make you more likely to participate?" and to "select all that apply" from a list of possible remedies (Fig. 2).

The most important facilitators for physical accessibility barriers were free transportation (61\%) and accessible locations (57\%). For communication barriers, key facilitators were communication of study results in understandable ways (62\%) and researchers' awareness of people with disabilities' needs (65\%). Other important facilitators were knowing that research participation will not incur costs for participants (59\%), the study is respectful of people with disabilities (58\%), and results of research will help people with disabilities (58\%). Forty-four percent of participants selected "having nonhospital settings for research visits" and 40\% "providing access to new medications and treatments from the study."

When asked about the importance of six different incentives for participation, most participants selected receiving personal health information (65\%), getting health care during the study $(60 \%)$ and payment for time (54\%). Free Internet was important to $48 \%$, with free smartphone and data plan (34\%) and free activity tracker (25\%) selected less frequently.

\section{Engagement}

Participants were first asked, "Should research participants and researchers be equal partners?" followed by "if you had the chance, how would you want to participate?" including several options: (1) "design," i.e., help design the study, choose research questions, and decide what kinds of research are conducted; (2) "data collection," i.e., help recruit other participants and collect study data; (3) "data analysis," i.e., help analyze data; and (4) "policy," i.e., help decide what to do with study results. Participants were also asked whether participants' engagement in the study would impact their willingness to participate.

The overwhelming majority of participants said they would want to participate in the study's design (86\%). Two-thirds wanted to participate in data collection (67\%), but only a third 


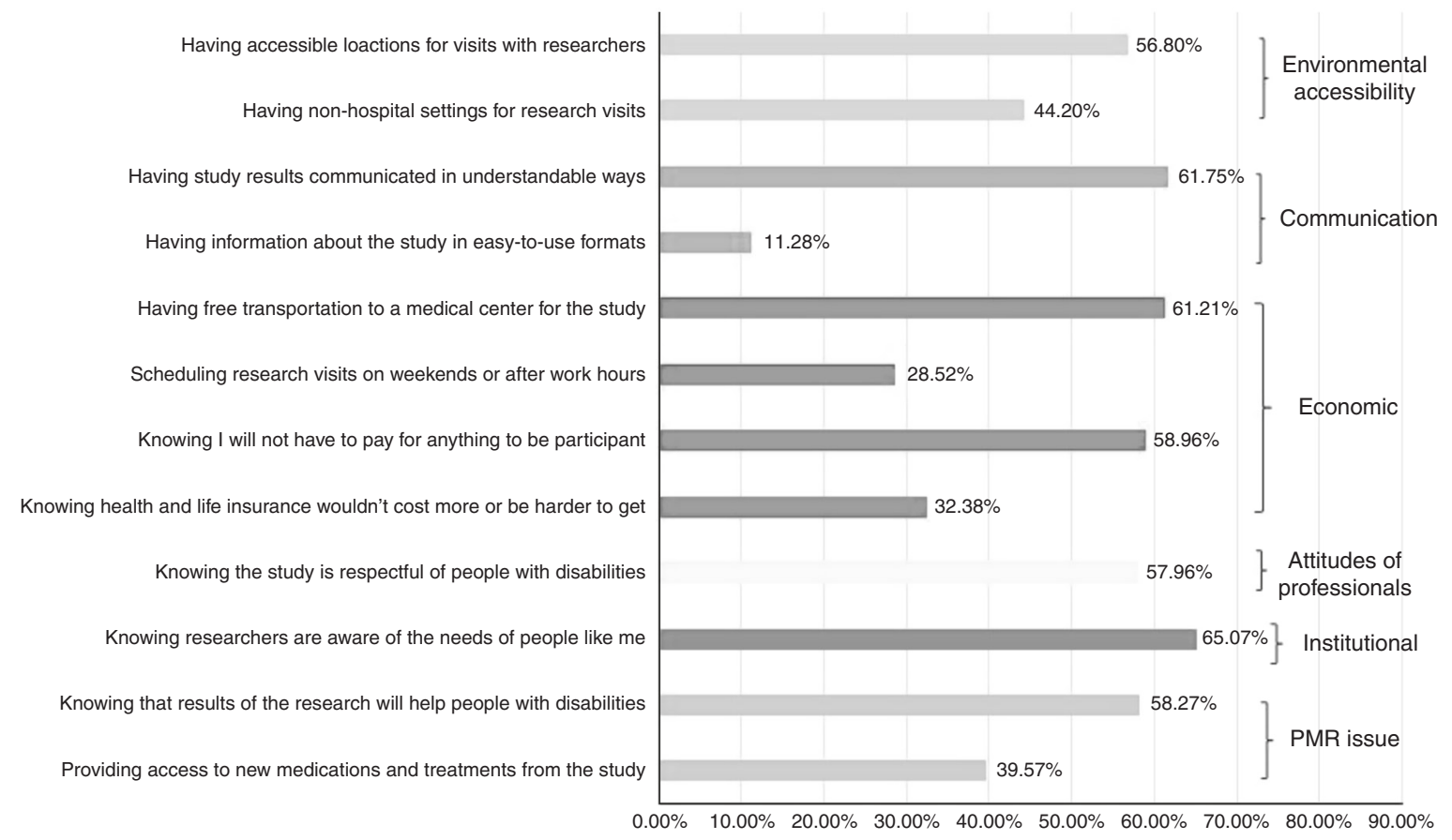

Fig. 2 Facilitators of participation $(\boldsymbol{n}=1294)$. PMR precision medicine research.

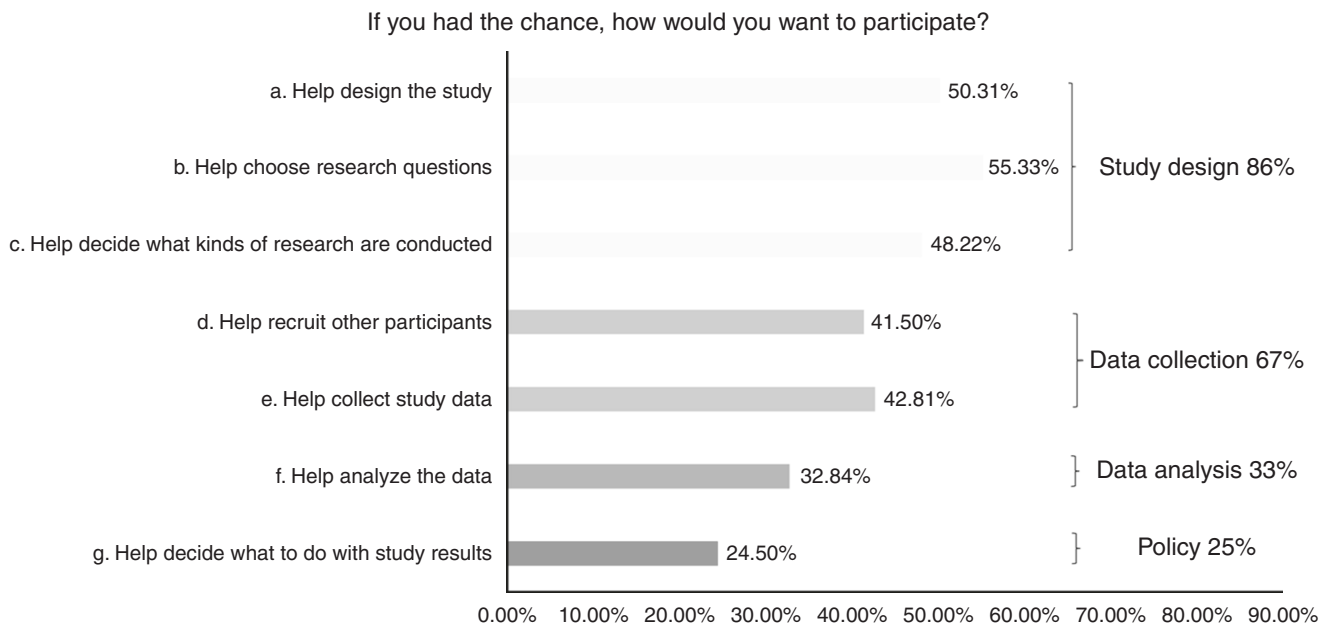

Fig. 3 Desired engagement of respondents in precision medicine research.

in data analysis (33\%), and fewer in postanalysis policy decisions (25\%) (Fig. 3). However, 70\% would be more willing to participate in the study if participants helped to plan and run it, and $84 \%$ said participants and researchers should be equal partners.

Differences were observed across ethnic, racial, and gender groups. Hispanic participants were more likely than nonHispanics to express willingness to engage in data collection $(p=0.0002)$ and data analysis $(p<0.0001)$, and less likely to want engagement in policy $(p<0.0001)$. White participants were more likely than the Other group to express interest in research design $(p<0.0001)$, data collection $(p<0.0001)$, and data analysis $(p=0.0021)$. White participants were more likely than Black/AA to express interest in policy $(p<0.0001)$, though Black/AA were more likely to express interest in study design $(p=0.0015)$. Men were more likely than women to express interest in data collection and less likely to want to engage in policy (both $p<0.0001$ ).

\section{DISCUSSION}

Although people with disabilities have often been prime targets for genomic research, their views on such research, and especially on PMR, are understudied. This survey offers a first insight into the views on PMR of a large sample of people with disabilities.

People with disabilities in our study, across racial/ethnic groups, expressed high support for PMR and willingness to participate in a longitudinal study (89\%), exceeding the 
interest found in previous studies on public support for a national biobank (69-82\%) (refs. ${ }^{20,21}$ ) and a national PMR cohort (33-56\%) (refs. ${ }^{10,22}$ ). This finding may indicate participants' interest in accessing health information and improved therapies, ${ }^{14}$ similar to the general population, ${ }^{2,5,10}$ but also interest in nonscientific benefits, e.g., a sense of equality, contribution, and belonging. ${ }^{23}$ Most of our participants were willing to provide lifestyle, biological, and medical information for PMR, though they were more selective about other data: half would not provide environmental samples, and most would not provide information from their social media account(s) and activity trackers. This suggests a desire for different levels of participation in PMR.

Disability scholars and activists have often raised concerns about genomic research and practices (e.g., prenatal testing), including fear that it will reinforce the medicalization of disabilities and increase stigma and discrimination against people with disabilities. ${ }^{13,24}$ Our findings indicate that many people with disabilities may share these concerns. Although our participants were as likely as participants from the general public to say they would provide blood (both $73 \%$ ) or other samples such as saliva (respectively, $73 \%$ vs. $75 \%$ ), the proportion of those willing to provide genetic and family history data was smaller ( $63 \%$ vs. $76 \%$ for genetic information; $59 \%$ vs. $77 \%$ for family medical history). ${ }^{10}$ Provision of such data was lower among some disability subgroups (autism, deafness, intellectual disabilities), for whom the medical model of disability has been particularly controversial. Moreover, lower percentages of women reported they would be willing to provide genetic data compared with men. This finding is interesting: studies of the general public often find higher interest in and uptake of genetic testing among women than men, ${ }^{25,26}$ suggesting that women carry the primary genetic responsibility for their families. ${ }^{27}$ Our finding, however, may reflect a unique concern among women with disabilities, who historically have been excluded from parenthood due to presumptions about the inheritance of their conditions and held blameworthy for their children's disabilities if they chose to procreate. ${ }^{28,29}$ Further research to explore how (and why) the intersection of disability and gender impacts willingness to provide genetic data is warranted.

Similarly, our participants expressed far less willingness than the general public to provide information from their activity trackers $\left(34 \%\right.$ vs. $75 \%$ [ref. $\left.\left.{ }^{10}\right]\right)$. This reluctance could reflect a worry about extensive medical surveillance, or a concern that disclosing such data might lead to prejudicial judgments about people with disabilities. As one participant commented: "It would [...] be nice if the [study's] results removed some stigma, particularly around people 'choosing' negative health outcomes (such as blaming weight on a moral failing)...."

The finding that our participants were more willing to provide biological and medical but not environmental samples was unexpected; it seems counterintuitive given decades of disability activism aimed at refocusing attention on environmental factors that impact health. ${ }^{14,30}$ One possible explanation is that our participants devalued environmental variables due to insufficient awareness of the importance of gene-environment interactions for health outcomes (like the general public $\left.{ }^{31}\right)$. However, this explanation, if correct, is unlikely to account for the entire difference between our participants' limited support and the reported high levels of support for such data provision among the general public (respectively, $51 \%$ vs. $83 \%$ [ref. ${ }^{10}$ ]).

Another possible explanation is that people with disabilities may be concerned about housing instability (as one participant stated: "[I] cannot predict 2 years if I am here or elsewhere") or about the consequences of revealing poor home environments such as soil contaminants or poor water quality. Research has shown that American society has often blamed the poor, especially racial/ethnic minorities, for their poverty, including poor living conditions and environmental degradation that may impact their families' health. ${ }^{32-34}$ People with disabilities, who are among the poorest populations in the United States, ${ }^{35}$ may share this concern. However, our findings only partly support this possibility. Although participants from racial/ethnic minorities expressed less willingness to provide environmental samples compared with White and non-Hispanic participants, participants with < $\$ 20,000$ household income were more likely than those with $>$ $\$ 56,000$ to do so. Further research into the reasons for this reluctance, including how disability, race, and ethnicity interact to impact willingness to provide environmental data, is needed.

Our finding of numerous barriers for disability inclusion in PMR is concerning. Although only $30 \%$ of our participants stated that their health conditions may impede participation, most participants identified 3-8 barriers to participation in PMR. Future studies could explore why White and male participants identified higher number of barriers (studies commonly suggest that health disparities are higher among women and non-White people with disabilities ${ }^{1,15}$ ). Regardless, our findings strongly support a key aspect of the social model of disability, ${ }^{14}$ the bedrock for the disability rights movement in the United States and elsewhere, namely that inaccessible and unaccommodating environments (rather than an individual's inability) prevent the full participation of people with disabilities in society. Indeed, although the hypothetical nature of responses to the survey may not translate into actual decisions to enroll in PMR, it is of note that a majority of participants said they would be more likely to participate if key barriers were removed.

Some of these barriers can be relatively easily addressed (e.g., costs of participation). Others will be more challenging. Studies indicate that many health-care facilities and medical equipment in the United States are inaccessible for people with disabilities ${ }^{36}$ and that researchers' and clinicians' knowledge of accommodations is limited. ${ }^{37,38}$ Offering accessible venues for participation in PMR and increasing professionals' disability-relevant knowledge will be essential. Removal of other barriers may be more challenging. "Harm in 
PMR," e.g., could reflect disability-specific concerns about eugenics, but also general concerns about privacy loss, requiring different responses. Similarly, participants' citation of access to new medications and treatments as a facilitator to participation may reflect worries that the data they provide may lead to benefits that they will not share. As these deficiencies may translate into decisions by people with disabilities not to participate in research, ${ }^{39,40}$ addressing them head-on will be key.

Engaging people with disabilities will be necessary for inclusive PMR to move forward. Most of our participants stated they would be more likely to participate if participants helped plan and run the study, and large fractions stated that they themselves would want to engage, primarily in study design and data collection. This enthusiasm exceeds previously reported engagement interest among participants from the general public ${ }^{10}$ and may reflect a desire to ensure that studies address health priorities that are pertinent to them. Participants' high engagement interest and belief that research participants should be equal partners may also reflect an effort to reclaim inclusion-in PMR, as elsewhereresonating with the ethos of "nothing about us without us."

Engagement of people with disabilities for PMR requires considerate, strategic planning. Although this population may have impairment(s) in common, it is highly heterogeneous medically, socioculturally, and in community structure (e.g., the Deaf community). Different subgroups (e.g., blind and deaf people) may require different measures for inclusion. People with similar impairments may view their conditions in significantly different ways and hold different visions for how their conditions play out in their lives. Engaging with subgroups of people with disabilities requires awareness of these differences, open-mindedness to using innovative research methods tailored to the needs of each subgroup, and building longstanding, colearning relationships of trust with disability communities. Such engagement will be essential to better understand the various needs of people with differing disabilities and necessary supports for active participation in PMR.

Our study has several potential limitations. Our sample of racial minorities other than Black/AA was small and precluded separate analysis. The online survey may have excluded people with disabilities without access to the Internet. The requirement that participants identify a primary disability might have unintentionally excluded some participants (e.g., deaf-blind who have two primary conditions). Finally, as our participants were members of collaborating organizations and relatively highly educated and prosperous, their views may not be entirely representative of the disabled population in the United States.

\section{Conclusion}

Disability inclusion in PMR is necessary for this population to enjoy the benefits of research and for promoting health equity. This first nationwide, large-scale study of people with disabilities indicates significant support for PMR, with a desire to engage as equal partners in many study-related decisions.

But this enthusiasm for PMR will not lead to actual participation unless the numerous physical, communication, institutional, and socioeconomic barriers that may preclude the participation of people with disabilities are addressed. Further research is needed to better understand the concerns that may impede participation and to develop educational materials on PMR that resonate with the interests and needs of this population and its subgroups. Moving forward to cultivate a genuine engagement with people with disabilities about PMR cannot start a minute too soon.

\section{SUPPLEMENTARY INFORMATION}

The online version of this article (https://doi.org/10.1038/s41436019-0486-1) contains supplementary material, which is available to authorized users.

\section{ACKNOWLEDGEMENTS}

This work was supported by National Human Genome Research Institute (NHGRI) grant K01HG008653, NHGRI/All of Us Research Program grant 3P50HG007257-05S1, and the National Institutes of Health (NIH) Office of the Director (OD). We gratefully acknowledge the support of the Association of University Centers on Disabilities (AUCD), the National Council on Independent Living (NCIL), National Federation of the Blind (NFB), the National Association of the Deaf (NAD), and the American Association of Health and Disability (AAHD), which assisted with recruitment, survey material, and programming. We also gratefully acknowledge the support of individuals who assisted in this process: Lou Ann Blake, Howard A. Rosenblum, Lizzie Sorkin, Abiodun Ramroop, Dawn Rudolph, Kelly Buckland, Cara Liebowitz, Mark Starford, Marcia Orland, Kecia Brooke Weller, Charlene Jones, Roberta Carlin, Carlos Ríos Espinosa, Anthony Stephens (American Council of the Blind), Amar D. Mandavia, and Dave Kaufman. Finally, we thank the numerous individuals who took the time to participate in our study.

\section{DISCLOSURE}

M.S. is a member of the All of Us Research Program's Institutional Review Board.

Publisher's note: Springer Nature remains neutral with regard to jurisdictional claims in published maps and institutional affiliations.

\section{REFERENCES}

1. Krahn GL, Walker DK, Correa-De-Araujo R. Persons with disabilities as an unrecognized health disparity population. Am J Public Health. 2015;105 suppl 2:S198-206.

2. Michie M, Henderson G, Garrett J, Corbie-Smith G. "If I could in a small way help": motivations for and beliefs about sample donation for genetic research. J Empir Res Hum Res Ethics. 2011;6:57-70.

3. Storr $\mathrm{CL}$, Or F, Eaton WW, lalongo N. Genetic research participation in a young adult community sample. J Community Genet. 2014;5:363-375.

4. Oliver JM, Slashinski MJ, Wang T, Kelly PA, Hilsenbeck SG, McGuire AL. Balancing the risks and benefits of genomic data sharing: genome research participants' perspectives. Public Health Genomics. 2012;15:106-114. 
5. Neidich AB, Joseph JW, Ober C, Ross LF. Empirical data about women's attitudes towards a hypothetical pediatric biobank. Am J Med Genet A. 2008;146a:297-304.

6. Kaufman D, Bollinger J, Dvoskin R, Scott J. Preferences for opt-in and optout enrollment and consent models in biobank research: a national survey of Veterans Administration patients. Genet Med. 2012;14:787-794.

7. Kaufman DJ, Murphy-Bollinger J, Scott J, Hudson KL. Public opinion about the importance of privacy in biobank research. Am J Hum Genet. 2009;85:643-654.

8. Hagiwara N, Berry-Bobovski L, Francis C, Ramsey L, Chapman RA, Albrecht TL. Unexpected findings in the exploration of African American underrepresentation in biospecimen collection and biobanks. J Cancer Educ. 2014;29:580-587.

9. Byrd GS, Edwards CL, Kelkar VA, Phillips RG, Byrd JR, Pim-Pong DS, et al. Recruiting intergenerational African American males for biomedical research studies: a major research challenge. J Natl Med Assoc. 2011;103:480-487.

10. Kaufman DJ, Baker R, Milner LC, Devaney S, Hudson KL. A survey of U.S adults' opinions about conduct of a nationwide Precision Medicine Initiative ${ }^{\circledR}$ Cohort Study of genes and environment. PLoS ONE. 2016;11:e0160461.

11. Kevles DJ. From eugenics to patents: genetics, law, and human rights. Ann Hum Genet. 2011;75:326-333.

12. Sabatello M. Children with psychiatric disabilities: bioethical \& genomic dilemmas. In: Ruck M, Peterson-Badali M, Freeman M, (eds.) The handbook of children's rights: global and multidisciplinary perspectives. Taylor and Francis; New York, NY, 2016. p. 328-346.

13. Parens $E$, Asch $A$. The disability rights critique of prenatal genetic testing. Reflections and recommendations. Hastings Cent Rep. 1999;29:S1-22.

14. Shakespeare T. Disability rights and wrongs revisited. New York: Routledge; 2014.

15. Wisdom JP, McGee MG, Horner-Johnson W, Michael YL, Adams E, Berlin M. Health disparities between women with and without disabilities: a review of the research. Social Work Public Health. 2010;25:368-386.

16. Williams AS, Moore SM. Universal design of research: inclusion of persons with disabilities in mainstream biomedical studies. Sci Transl Med. 2011;3:82 cm12

17. World Health Organization, The World Bank. World report on disability. Malta 2011. https://www.who.int/disabilities/world_report/2011/report. pdf?ua=1. Accessed 18 March 2019.

18. Null R. Universal design: principles and models. Boca Raton, FL: CRC Press; 2014

19. Cornell University. Disability statistics: online resource for U.S. disability statistics. 2018. http://mww. disabilitystatistics.org/reports/acs.cfm?statistic=6. Accessed 18 March 2019.

20. Kaufman D, Murphy J, Erby L, Hudson K, Scott J. Veterans' attitudes regarding a database for genomic research. Genet Med. 2009;11:329.

21. Rahm AK, Wrenn M, Carroll NM, Feigelson HS. Biobanking for research: a survey of patient population attitudes and understanding. J Community Genet. 2013;4:445-450.

22. Halbert $\mathrm{CH}, \mathrm{McD}$ nald J, Vadaparampil S, Rice $L$, Jefferson $M$. Conducting precision medicine research with African Americans. PLoS ONE. 2016;11:e0154850.
23. McDonald KE, Schwartz NM, Gibbons CM, Olick RS. "You can't be cold and scientific": community views on ethical issues in intellectual disability research. J Empir Res Hum Res Ethics. 2015;10:196-208.

24. Scully JL. Disability and genetics in the era of genomic medicine. Nat Rev Genet. 2008;9:797-802.

25. Denayer L, Boogaerts A, Philippe K, Legius E, Evers-Kiebooms G. BRCA1/ 2 predictive testing and gender: uptake, motivation and psychological characteristics. Genet Couns. 2009;20:293-305.

26. Sabatello M, Chen Y, Sanderson SC, Chung WK, Appelbaum PS. Increasing genomic literacy among adolescents. Genet Med. 2018. https://doi.org/10.1038/s41436-018-0275-2. [Epub ahead of print].

27. d'Agincourt-Canning L, Baird P. Genetic testing for hereditary cancers: the impact of gender on interest, uptake and ethical considerations. Crit Rev Oncol Hematol. 2006;58:114-123.

28. Sabatello M. Disability, human rights, and global health. In: Freeman $M$, Hawkes S, Bennett B, (eds.) Law and global health: current legal issues. Oxford: Oxford University Press; 2014. p. 244-263.

29. National Council on Disability. Rocking the cradle: ensuring the rights of parents with disabilities and their children. 2012. https://ncd.gov/ publications/2012/Sep272012/2012. Accessed 18 March 2019.

30. Sabatello M. A short history of the international disability rights movement. In: Sabatello $M$, Schulze $M$, (eds.) Human rights and disability advocacy. Philadelphia, PA: University of Pennsylvania Press; 2014. p. 13-24.

31. Heine SJ, Dar-Nimrod I, Cheung BY, Proulx T Chapter Three - Essentially Biased: Why People Are Fatalistic About Genes. In: Olson JM, edi. Adv Exp Soc Psychol: Academic Press; 2017. Vol. 55, p. 137-192.

32. Fentiman LC. Are mothers hazardous to their children's health? Law, culture and the framing of risk. Va J Soc Policy Law. 2014;21: 295-340.

33. Greenbaum SD. Blaming the poor: the long shadow of the Moynihan Report on cruel images about poverty. Rutgers University Press; New Brunswick, New Jersey, 2015

34. Fentiman LC. Blaming mothers: American law and the risks to children's health. New York: NYU Press; 2017.

35. Kraus L. 2016 Disability statistics annual report. https://disabilitycompendium. org/sites/default/files/user-uploads/2016_AnnualReport.pdf. Institute on Disability/UCED; Durham, NH, 2017. Accessed 18 March 2019.

36. Mudrick NR, Breslin ML, Liang M, Yee S. Physical accessibility in primary health care settings: results from California on-site reviews. Disabil Health J. 2012;5:159-167.

37. Pharr J. Accessible medical equipment for patients with disabilities in primary care clinics: why is it lacking? Disabil Health J. 2013;6: 124-132.

38. Withers J, Speight $C$. Health care for individuals with hearing loss or vision loss: a minefield of barriers to accessibility. N C Med J. 2017;78:107-112.

39. Rios D, Magasi S, Novak C, Harniss M. Conducting accessible research: Including people with disabilities in public health, epidemiological, and outcomes studies. Am J Public Health. 2016;106:2137-2144.

40. Sabatello M. Precision medicine, health disparities, and ethics: the case for disability inclusion. Genet Med. 2018;20:397-399. 